\title{
Ethanol Affects Striatal Interneurons Directly and Projection Neurons Through a Reduction in Cholinergic Tone
}

\author{
Craig P Blomeley', Sarah Cains', Richard Smith' and Enrico Bracci*,' \\ 'Faculty of Life Sciences, University of Manchester, Manchester, UK
}

\begin{abstract}
The acute effects of ethanol on the neurons of the striatum, a basal ganglia nucleus crucially involved in motor control and action selection, were investigated using whole-cell recordings. An intoxicating concentration of ethanol (50 mM) produced inhibitory effects on striatal large aspiny cholinergic interneurons (LAls) and low-threshold spike interneurons (LTSIs). These effects persisted in the presence of tetrodotoxin and were because of an increase in potassium currents, including those responsible for medium and slow afterhyperpolarizations. In contrast, fast-spiking interneurons (FSIs) were directly excited by ethanol, which depolarized these neurons through the suppression of potassium currents. Medium spiny neurons (MSNs) became hyperpolarized in the presence of ethanol, but this effect did not persist in the presence of tetrodotoxin and was mimicked and occluded by application of the MI muscarinic receptor antagonist telenzepine. Ethanol effects on MSNs were also abolished by $100 \mu \mathrm{M}$ barium. This showed that the hyperpolarizations observed in MSNs were because of decreased tonic activation of $\mathrm{MI}$ muscarinic receptors, resulting in an increase in Kir2 conductances. Evoked GABAergic responses of MSNs were reversibly decreased by ethanol with no change in paired-pulse ratio. Furthermore, ethanol impaired the ability of thalamostriatal inputs to inhibit a subsequent corticostriatal glutamatergic response in MSNs. These results offer the first comprehensive description of the highly cell type-specific effects of ethanol on striatal neurons and provide a cellular basis for the interpretation of ethanol influence on a brain area crucially involved in the motor and decisional impairment caused by this drug. Neuropsychopharmacology (20II) 36, 1033-1046; doi: 10.1038/npp.2010.24I; published online 2 February 201 I
\end{abstract}

Keywords: striatum; ethanol; basal ganglia; cholinergic interneuron; fast-spiking interneuron; medium spiny neuron

\section{INTRODUCTION}

Ethanol is one of the most widely used and abused psychoactive drugs, and it produces a variety of acute and chronic effects (Ferreira and Willoughby, 2008). Serious social problems arise from the fact that acutely intoxicated subjects exhibit a combination of impaired sensory-motor coordination and diminished control of impulsive and aggressive behavior (Naranjo and Bremner, 1993). How does ethanol affect the brain? Although initial hypotheses pointed to an action on the physical properties of the lipid bilayer (affecting ion channels indirectly), subsequent studies focused on the direct modulation of GABAergic transmission by ethanol (Mihic et al, 1997). It has since become progressively clear that ethanol directly affects the activity of numerous membrane proteins, including both ligand-gated and voltage-gated channels (Harris et al, 2008).

\footnotetext{
*Correspondence: Dr E Bracci, Faculty of Life Sciences, University of Manchester, A.V Hill Building, Manchester MI3 9PT, UK, Tel: + 44 (0) I6I 3065765, Fax: +44(0) I6I 2753938, E-mail: e.bracci@manchester.ac.uk

Received 26 August 2010; revised 30 November 2010; accepted 13 December 2010
}

The biophysical mechanisms underlying ethanol-protein interactions have started to be elucidated (Aryal et al, 2009; Dopico and Lovinger, 2009; Harris et al, 2008). Brain slice preparations have been particularly useful to study the acute effects of ethanol on several brain areas, including the cerebral cortex, the amygdala, the ventral tegmental area, and the cerebellum (Carta et al, 2003, 2004; Federici et al, 2009; Sessler et al, 1998; Zhu and Lovinger, 2006). The picture emerging from these studies is that the effects of ethanol are highly specific both in terms of brain areas and neuronal types. Thus, ethanol can either increase or decrease the excitability of different neurons, and either reduce or potentiate fast synaptic transmission. For instance, ethanol increases Golgi cells' excitability (Carta et $a l, 2004)$, whereas it reduces that of somatosensory cortical neurons (Sessler et al, 1998). Similarly, ethanol potentiates responses mediated by $\mathrm{GABA}_{\mathrm{A}}$ receptors in most brain areas (Weiner and Valenzuela, 2006), but it reduces them in the ventral tegmental area (Xiao and Ye, 2008). Glutamatergic responses mediated by AMPA receptors are potentiated by ethanol in the ventral tegmental area (Deng et al, 2009), whereas they are reduced in cerebellar granule cells (Valenzuela et al, 1998). These differences reflect the highly specific interactions of ethanol with 
different subunits of receptors and ion channels (Aryal et al, 2009; Vengeliene et al, 2008). Given this degree of heterogeneity, it is clear that the effects of ethanol on different brain areas must be directly investigated and cannot be inferred from studies carried out in other structures. The striatum is the largest nucleus of the basal ganglia and is likely to be crucially involved in the motor and emotional effects of ethanol. First, this nucleus has an essential role in motor control and its malfunctioning results in severe neurological diseases (Graybiel, 2005; Redgrave and Coizet, 2007). Furthermore, the involvement of the dorsal striatum in reward processing, rewardmediated learning, and drug addiction is well established (Balleine et al, 2007; Koob and Volkow, 2010; Surmeier et al, 2009; Wickens et al, 2007b). Nevertheless, our understanding of the effects of ethanol on the striatum is still incomplete. Previous investigations of the acute effects of ethanol on the striatum have focused on the glutamatergic responses of projection neurons and their plasticity (Popp et al, 1998; Wang et al, 2007; Yin et al, 2007). Although these studies have provided important information, a more complete picture requires specific knowledge of how ethanol affects each of the neuronal types found in the striatum, as well as of GABAergic responses of striatal projection neurons. In this study we report that three classes of striatal interneurons are strongly and specifically modulated by intoxicating concentrations of ethanol, whereas striatal projection neurons are affected through decreased cholinergic tone and downregulation of their fast synaptic inputs.

\section{MATERIALS AND METHODS}

Sprague Dawley rats (both sexes, postnatal days 14-26, supplied by Biological Services Facility, University of Manchester, UK) were used for the experiments on large aspiny cholinergic interneurons (LAIs), fast-spiking interneurons (FSIs), and medium spiny neurons (MSNs), and some of the experiments on low-threshold spike interneurons (LTSIs). Overall, the average age of the animal used was $18 \pm 3$ days postnatal; the average age of the animals used for experiments on different neuronal types was as follows (in days): LAIs, $17 \pm 2$; FSIs, $20 \pm 3$; LTSIs $18 \pm 2$; and MSNs, $18 \pm 3$. Several developmental events take place during the third week of life in rats (Partridge et al, 2000; Plotkin et $a l, 2005)$; in order to determine if there were developmental changes in the responses of striatal neurons to ethanol, we considered separately the experiments carried out in animals aged P14-P20 and P21-P26 days $(n \geqslant 9$ for each group for each neuronal type). The effects of ethanol on the membrane potential (or interspike interval (ISI) for LAIs) and input resistance in each neuronal type were not significantly different in the two groups; furthermore, the percentage of cells that responded to ethanol was similar in the two groups for each neuronal type. Therefore, results from all animals were pooled for analysis in the Results.

In other experiments, LTSIs were visually identified using bacteria artificial chromosome (BAC) mice (P14-30; average $22 \pm 5$ days), in which the neuropeptide Y (NPY) promoter was attached to a humanized Renilla GFP (BACnpy; Stock 006417; Jackson Laboratory, Bar Harbor, ME); these mice were bred in-house at the Biological Services Facility, University of Manchester. NPY-expressing neurons in the striatum coincide with LTSIs (Partridge et al, 2009). GFP-positive neurons were identified through epifluorescent excitation of the slice with a mercury lamp (Olympus U-RFL-T) coupled with standard GFP filters.

As in rats, similar responses to ethanol were observed in LTSIs from P14 to P20 and from P21 to P30 mice. Furthermore, similar responses to ethanol were observed in LTSIs from rats and mice in current-clamp experiments (voltage-clamp experiments were carried out exclusively on LTSIs from mice slices).

All the animals were killed using cervical dislocation, a humane method of killing in accordance with the UK Animals (Scientific Procedures) Act 1986 and the European Communities Council Directive (86/609/EEC).

Sagittal or horizontal brain slices $(250-300 \mu \mathrm{m}$ thick) were obtained using a vibroslicer and maintained at $25^{\circ} \mathrm{C}$ in oxygenated artificial cerebrospinal fluid (composition (in $\mathrm{mM}$ ): $126 \mathrm{NaCl}, 2.5 \mathrm{KCl}, 1.3 \mathrm{MgCl}_{2}, 1.2 \mathrm{NaH}_{2} \mathrm{PO}_{4}, 2.4 \mathrm{CaCl}_{2}$, 10 glucose, and $\left.18 \mathrm{NaHCO}_{3}\right)$. For recordings, slices were submerged, superfused $(2-3 \mathrm{ml} / \mathrm{min})$ at $25^{\circ} \mathrm{C}$, and visualized with infrared/differential interference contrast microscopy. Horizontal slices preserving thalamostriatal and corticostriatal fibers were obtained as described in previous studies (Deschenes et al, 1996; Smeal et al, 2007).

Current-clamp recordings were performed in bridge mode using an Axoclamp-2B amplifier (Axon Instruments) or a BA-1S bridge amplifier (NPI Electronic $\mathrm{GmbH}$ ). Voltage-clamp recordings were performed using the AxoClamp-2B in continuous single-electrode mode, with uncompensated series resistance or a SEC-10LX (NPI Electronic $\mathrm{GmbH}$ ) in discontinuous single-electrode mode. Data were acquired at $10 \mathrm{kHz}$ using Signal software and a micro1401 data acquisition unit (C.E.D. UK). Data analysis was carried out using Signal and Spike (C.E.D) and Matlab (MathWorks) software.

Conventional whole-cell recordings were performed with patch pipettes (3-5 M $\Omega$ ) filled with a solution containing (in $\mathrm{mM}$ ): 125 potassium gluconate, $10 \mathrm{NaCl}, 1 \mathrm{CaCl}_{2}, 2 \mathrm{MgCl}_{2}, 1$ BAPTA, 19 HEPES, $0.4 \mathrm{Mg}$-GTP, and $4 \mathrm{Mg}$-ATP, and adjusted to $\mathrm{pH} 7.3$ with $\mathrm{KOH}$ (except when recording GABAergic events, see below). In some experiments, highchloride intracellular solution was used, obtained by substituting potassium gluconate with potassium chloride; with this solution, the nominal reversal potential for chloride $\left(\mathrm{E}_{\mathrm{cl}}\right)$ was $=1 \mathrm{mV}$, compared with $-55 \mathrm{mV}$ with normal intracellular solution. For perforated-patch recordings, gramicidin $(10-20 \mu \mathrm{g} / \mathrm{ml})$ was added to the normal intracellular solution and perforation was monitored as previously described (Blomeley and Bracci, 2005). In these recordings, the apparent electrode resistance (which incorporated the perforated-patch resistance and was regularly compensated in bridge mode) was 3-40 $\mathrm{M} \Omega$ and did not change by $>30 \%$ during each experiment.

Resting membrane potential (RMP) was measured under current-clamp conditions in the absence of any injected current. Input resistance was measured in current-clamp experiments by applying small negative current steps (0.5$1 \mathrm{~s}$ long), eliciting $2-10 \mathrm{mV}$ deflections and applied continuously every 10-20 s. If the neuron was depolarized or hyperpolarized as a result of a pharmacological treatment, it 
was manually repolarized to control level for a short period while the current steps were applied; in this way, input resistance measurements were obtained at the same membrane potential. The input resistance was calculated by dividing the steady-state voltage deflection (measured at the end of the step) by the amplitude of the current step. For each pharmacological condition tested, 10-25 current steps were applied at $10 \mathrm{~s}$ intervals; the input resistance measurements for each condition were then grouped for statistical analysis.

Slow voltage ramps $(10 \mathrm{mV} / \mathrm{s})$ were applied in voltageclamp mode; in experiments with FSIs, the pre-ramp holding potential was $-80 \mathrm{mV}$ and the ramp started from $-120 \mathrm{mV}$; for LTSIs, pre-ramp holding potential was $-60 \mathrm{mV}$ and the ramp started from $-110 \mathrm{mV}$. In order to avoid transient currents at the beginning of the ramp, these ramps were preceded either by a 1-s step to $-120 \mathrm{mV}$ (in FSI experiments) or by a negative ramp $(-10 \mathrm{mV} / \mathrm{s})$ from -60 to $-110 \mathrm{mV}$ (in LTSI experiments).

For action potential half-width measurements, the spike threshold was defined as the point where the rate of depolarization exceeded $75 \mathrm{mV} / \mathrm{ms}$; spike amplitude was measured as the difference between the threshold level and the peak of the spike.

Drugs were prepared in stock solutions and bath applied at known concentrations via a gravity system. Ethanol (95\%, spectrophotometric grade) from Fisher Scientific (Loughborough, UK) was applied for $5-15 \mathrm{~min}$ at $50 \mathrm{mM}$, a concentration that produces intoxication in humans and has been used in previous in vitro studies (Carta et al, 2004; Lovinger et al, 1989; Yin et al, 2007). Dose-response experiments carried out in LTSIs and MSNs (in the range of $12.5-100 \mathrm{mM}$ ) revealed that the effects of ethanol on membrane potential were maximal at $50 \mathrm{mM}$, and produced estimated $\mathrm{EC}_{50}$ values of $27 \mathrm{mM}$ for MSNs and $29 \mathrm{mM}$ for LTSIs. These experiments are illustrated in Supplementary Figure 1.

Drugs were obtained from Tocris Bioscience (Poole, UK), apart from gramicidin $(10-20 \mu \mathrm{g} / \mathrm{ml})$, which was obtained from Sigma-Aldrich (Bristol, UK).

GABAergic responses were isolated pharmacologically and recorded or in voltage-clamp as inhibitory postsynaptic currents (IPSCs). GABAergic responses were evoked with a monopolar stimulating electrode, consisting of a patch micropipette filled with ACSF, placed intrastriatally. The resistance of the micropipettes used for stimulation was $0.3-1 \mathrm{M} \Omega$. Stimulation amplitude was $0.2 \mu \mathrm{A}-3.2 \mathrm{~mA}$, and its duration was $0.01-0.1 \mathrm{~ms}$. GABAergic responses were recorded under voltage-clamp conditions $\left(V_{\mathrm{h}}=-80 \mathrm{mV}\right)$ using the high-chloride intracellular solution described above, in order to increase the driving force for $\mathrm{GABA}_{\mathrm{A}}$ conductances. These experiments were carried out in the presence of the AMPA receptor antagonist 2,3-dihydroxy-6nitro-7-sulfonyl benzo[f] quinoxaline (NBQX; $10 \mu \mathrm{M})$ and the NMDA receptor antagonist AP-5 $(10 \mu \mathrm{M})$. Under these conditions, evoked responses were completely abolished by the $\mathrm{GABA}_{\mathrm{A}}$ receptor antagonist bicuculline methiodide, consistent with the finding that postsynaptic $\mathrm{GABA}_{\mathrm{B}}$ receptor-mediated responses are not detected in MSNs (Calabresi et al, 1992).

Paired-pulse stimulation (200 ms interval) was applied every $10 \mathrm{~s}$ before, during, and after ethanol application.
Different paired-pulse intervals were chosen to allow a complete return to baseline of the evoked responses in the two cases. For each cell, statistical tests were carried out on groups of at least 10 consecutive responses for each pharmacological condition tested.

In the experiments with horizontal slices, a stimulating electrode was placed in the deep layers of the cortex, while another one was placed in the thalamic reticular nucleus, as described by Ding et al (2010). These stimulators were used to activate corticostriatal and thalamostriatal fibers, respectively. In these experiments, carried out in current-clamp in the presence of bicuculline methiodide $(20 \mu \mathrm{M})$, a single cortical stimulation was delivered every $20 \mathrm{~s}$; every other cortical stimulation was preceded $(5 \mathrm{~s})$ by a train of 25 thalamic stimuli delivered at $50 \mathrm{~Hz}$. For analysis, corticostriatal EPSP amplitudes for each condition (ie, those preceded or not preceded by a thalamic train) were averaged and compared statistically.

Experimental values are expressed as mean \pm SD and all statistical comparisons were evaluated using Student's $t$-test. The threshold level of significance for all analyses was $P<0.05$. When only a subgroup of neurons responded to ethanol, the analysis of ethanol effects was limited to the responsive cells. Changes in input resistance during pharmacological treatments were assessed statistically for each individual neuron, comparing the amplitude of consecutive current pulses (at least 20) in each condition.

\section{RESULTS}

We recorded from 66 striatal MSNs, 36 FSIs, and 54 LTSIs using conventional whole-cell techniques, and from 57 LAIs using gramicidin perforated-patch techniques (Blomeley and Bracci, 2005). All neurons were recorded in the rostral part of the dorsolateral striatum.

As in previous studies (Blomeley and Bracci, 2009; Blomeley et al, 2009; Bracci et al, 2003; Centonze et al, 2002; Pakhotin and Bracci, 2007), neuronal types were identified based on their distinctive electrophysiological properties (described below) and, in the case of LAIs, their large cell body size (Kawaguchi, 1993). In experiments using BAC-npy mice, epifluorescence was additionally used to target neurons expressing GFP (see Materials and Methods for details).

\section{Effects of Ethanol on Cholinergic Interneurons}

The electrophysiological properties of LAIs undergo severe rundown when conventional whole-cell recordings are carried out (Blomeley and Bracci, 2005; Wilson, 2005). Therefore, we used the gramicidin perforated-patch technique in order to investigate the effects of ethanol on these cells. This technique is unsuitable for voltage-clamp because of the large access resistance. Therefore, this part of the study was entirely carried out under current-clamp conditions.

Typical LAI properties included: (1) prominent medium afterhyperpolarizations (mAHPs) following individual spikes; (2) slow afterhyperpolarizations (sAHP) following trains of action potentials evoked by current injections; and (3) depolarizing sags that developed during 

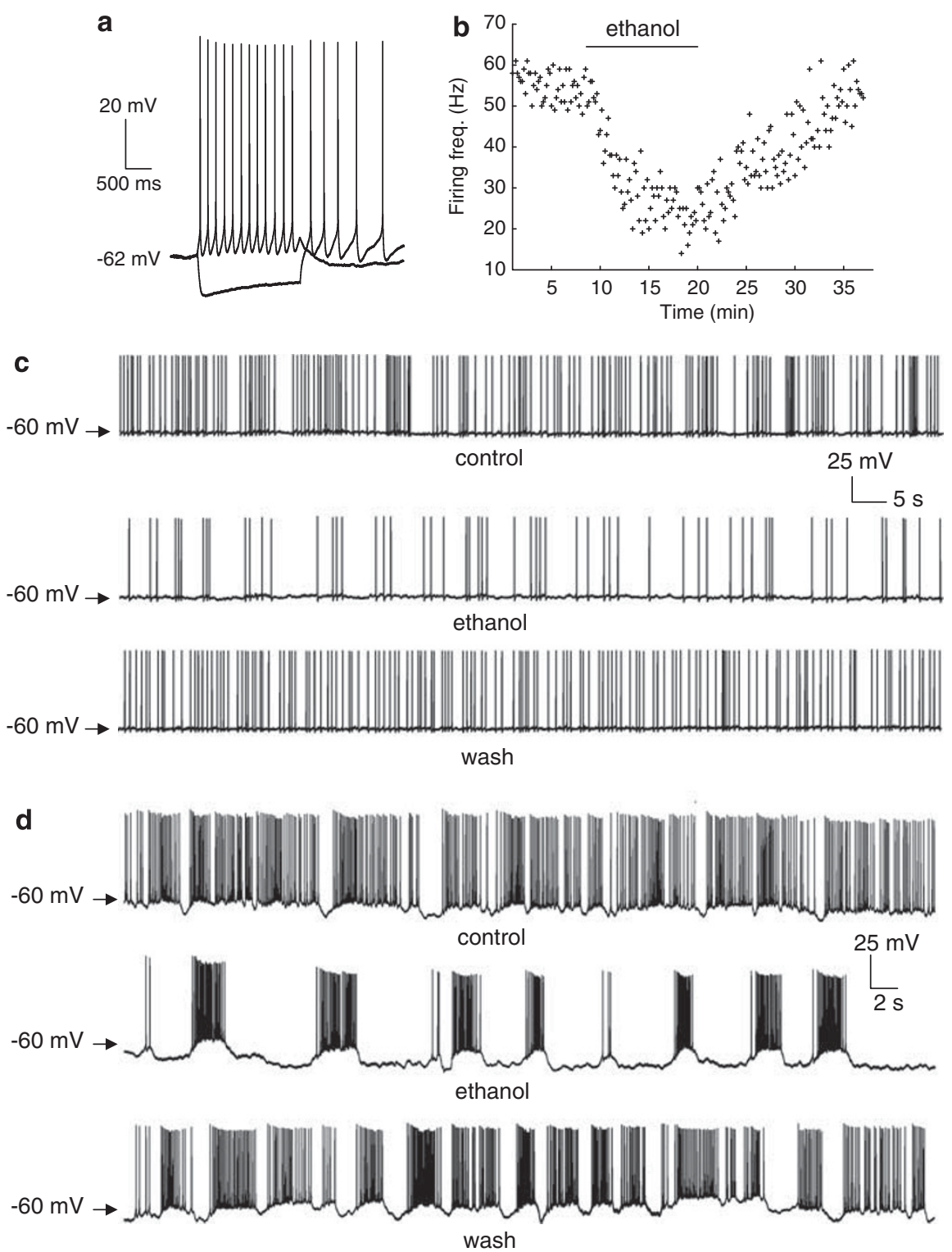

Figure I Inhibitory effects of ethanol on LAls. (a) Typical responses of a cholinergic interneuron to current injections ( $\pm 100 \mathrm{pA}$ ). (b) Distribution of firing frequencies (measured over consecutive periods of $2400 \mathrm{~s}$ ) before, during, and after ethanol application ( $50 \mathrm{mM}$ in this and subsequent figures). Responses are from the LAI in (c). (c) Bath application of ethanol reversibly decreased spike frequency in a LAl that displayed regular spontaneous firing in control solution. (d) Bath application of ethanol strongly and reversibly decreased spike frequency in a LAl that displayed burstiform spontaneous firing rate in control solution. On average, firing frequency (measured over a 5-min period for each pharmacological condition) was $4.9 \mathrm{~Hz}$ in control, $2.8 \mathrm{~Hz}$ in ethanol, and $3.4 \mathrm{~Hz}$ after ethanol washout.

current-induced hyperpolarization (Bennett et al, 2000; Wilson, 2005), as shown in Figure 1a.

As previously reported (Bennett et al, 2000), most LAIs (46/57) were spontaneously active. Among these cells, 44 displayed a regular firing activity (coefficient of variation of the ISI $<30 \%$ ), whereas the remaining 2 produced a burstiform activity (coefficient of variation of the ISI $>50 \%$ ); examples of the two types of activity are shown in Figure $1 \mathrm{c}$ and $\mathrm{d}$. Overall, the average ISI in control ACSF ranged from 0.17 to $9.93 \mathrm{~s}$ (corresponding to frequencies ranging from 0.1 to $5.9 \mathrm{~Hz}$ ). The average ISI across the spontaneously active cells was $1.37 \pm 0.81 \mathrm{~s}$ (corresponding to $0.73 \pm 0.43 \mathrm{~Hz}$ ). The average input resistance was $388 \pm 67 \mathrm{M} \Omega$. In the $11 \mathrm{LAIs}$ that were not spontaneously active, the average RMP was $-64 \pm 4 \mathrm{mV}$.
In all spontaneously active LAIs, ethanol significantly $(P<0.05)$ increased the average ISI (on average, by $34 \pm 17 \%$ ); this corresponds to a $25 \pm 9 \%$ decrease in average firing frequency.

The effects of ethanol were reversible on washout (on average, after ethanol washout, ISI returned to $94 \pm 3 \%$ of control). Two representative examples of the effects of ethanol on two LAIs with different types of spontaneous firing in control solution are shown in Figure 1c and d. In the 11 LAIs that were not spontaneously active, ethanol did not cause significant changes in membrane potential.

LAIs display a prominent cationic current activated by hyperpolarization (Wilson and Goldberg, 2006), which is modulated by several neurotransmitters (Pisani et al, 2003); this current gives rise to slow depolarizing sags during 
negative current injections (Bennett et al, 2000), as apparent in Figure 1a. We therefore tested whether the depolarizing sags were affected by ethanol. In these experiments, in the presence of ethanol, the LAIs were manually depolarized to control level and the negative current steps were adjusted to match the initial deflection observed in control solution. However, the extent and time course of the depolarizing sags were not significantly affected by ethanol $(n=15$; not shown).

Another prominent current in LAIs is the apaminsensitive, calcium-activated potassium current, which gives rise to the mAHPs that follow individual spikes (Bennett et al, 2000). The amplitude of the mAHP (measured from spike threshold level to the negative peak following the spike) was on average $5.6 \mathrm{mV}$. The $\mathrm{mAHP}$ was strongly and reversibly increased by ethanol (by $25 \pm 9 \% ; P<0.01 ; n=6$ ), as shown in Figure 2a and c.

Positive current injections that elicit or increase firing in LAIs are followed by large-amplitude sAHPs that last several seconds (Wilson and Goldberg, 2006). We tested whether ethanol affected the sAHP. As the amplitude of the sAHP depends on the number of spikes generated, in the presence of ethanol we manually clamped the cell at a membrane potential level similar to that observed in control solution, and injected current steps (0.05-0.12 nA) that elicited the same number of spikes as in control. As shown in Figure $2 \mathrm{~b}$ and $\mathrm{c}$, the amplitude of the SAHPs was strongly increased in the presence of ethanol, and this effect was reversed by subsequent washout. On average, in five LAIs, ethanol significantly $(P<0.01)$ increased the sAHP amplitude to $135 \%$ of control.

In order to isolate LAIs from spike-dependent synaptic influences, we then carried out experiments in the presence of TTX. Under these conditions, ethanol did not affect LAI RMP $(n=4)$, as shown in Figure 3a. Long ( $2 \mathrm{~s})$ current injections (0.05-0.1 nA) elicited $30-40 \mathrm{mV}$ depolarizations followed (during the current step) by hyperpolarizing sags and (after the step) by AHPs. These voltage trajectories are caused by activation of calcium-activated potassium currents that are also responsible for the sAHPs evoked by bursts of action potentials (Blomeley and Bracci, 2005). In the presence of ethanol, in 5/5 LAIs both the hyperpolarizing sags and the AHPs increased significantly, as shown in Figure $3 \mathrm{~b}$ and quantified by the plots of Figure $3 \mathrm{c}$. In these experiments, the depolarizing current was maintained at the same level in control solution and in the presence of ethanol, and 10 consecutive steps were applied every $30 \mathrm{~s}$ in each pharmacological condition. The effects of ethanol on these waveforms were largely reversed upon washout (Figure 3b).

We concluded that ethanol strongly reduces the excitability of LAIs by potentiating the calcium-activated potassium currents responsible for mAHP and sAHP.

\section{Effects of Ethanol on FSIs}

FSI membrane properties included: (1) intermittent firing at high frequency during positive current injections; (2) narrow action potentials; (3) large amplitude, shortduration spike afterpolarizations; and (4) subthreshold oscillations observed between spike bursts (Bracci et al, 2003; Kawaguchi, 1993; Koos and Tepper, 1999). Examples a
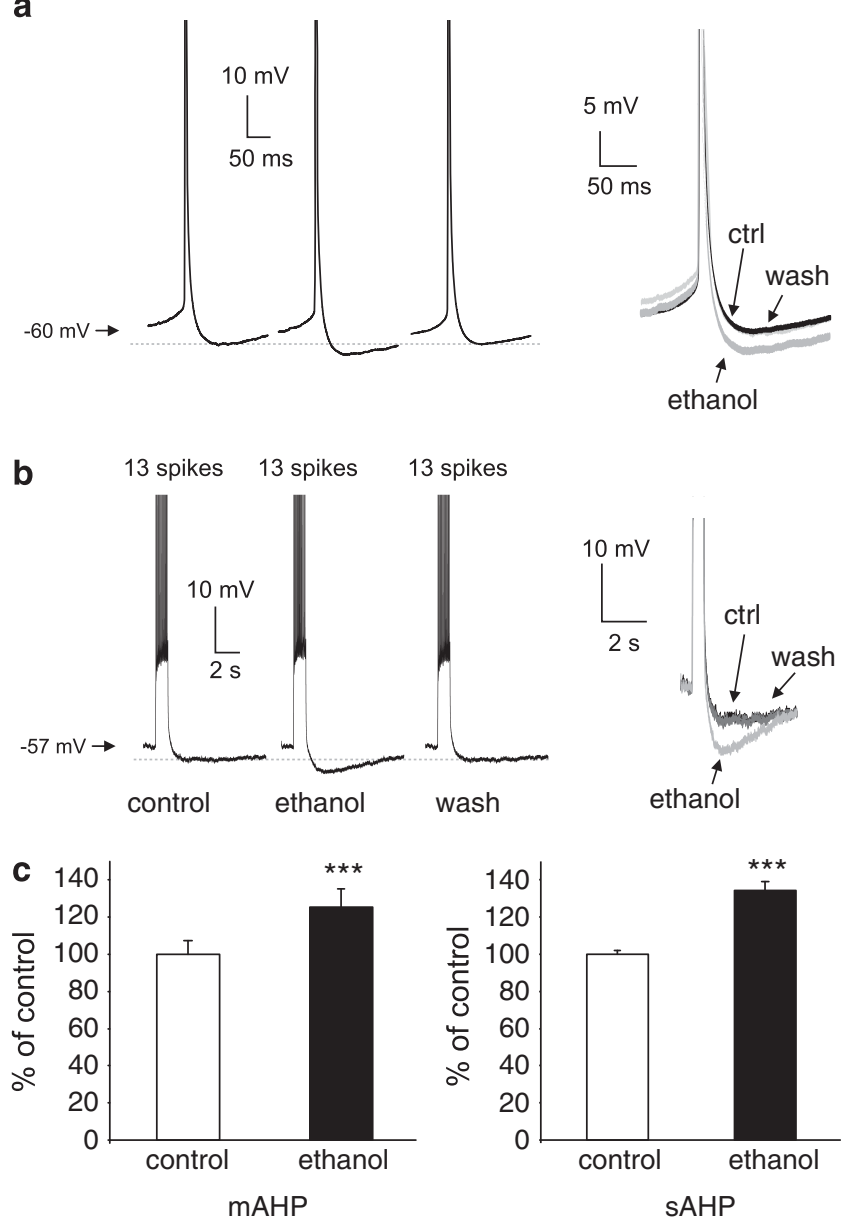

Figure 2 Ethanol reduces the mAHPs and sAHPs in LAls. (a) Ethanol application reversibly reduced the mAHP following individual spikes in LAls. Each trace represents the average of 10 events. Traces for each condition are superimposed on the right. Spikes are truncated. (b) In control solution, positive current injections producing 13 spikes were followed by slow AHPs in a LAl manually repolarized at $-57 \mathrm{mV}$ to prevent spontaneous spikes. In the presence of ethanol, the same LAI was manually polarized at the same level observed in control solution, and injected with current steps that elicited 13 spikes. Under these conditions, ethanol strongly increased the sAHPs following the current steps and this effect was reversed by subsequent washout. Individual traces are superimposed on the right. Spikes are truncated. (c) Average effects of ethanol on the mAHP (left) and sAHP (right) amplitude (data from five LAls were normalized to average value observed in control solution $(100 \%))$. ${ }^{*} * * P<0.001$.

of these properties are shown in Figure 4a. The average RMP of the FSIs was $-68 \pm 3 \mathrm{mV}$ and the average input resistance was $226 \pm 19 \mathrm{M} \Omega$.

Unlike LAIs, FSIs were recorded with conventional whole-cell techniques, as the properties of these cells do not undergo significant rundown under these conditions (Blomeley and Bracci, 2009). In all the FSIs tested $(n=32)$, application of ethanol in control ACSF elicited a reversible membrane depolarization (Figure $4 \mathrm{~b}$ ). On average, the peak amplitude of ethanol-induced depolarizations was $7 \pm 3 \mathrm{mV}$. In four FSIs where the RMP was more depolarized than average $(63 \pm 2 \mathrm{mV})$, application of ethanol also caused the appearance of spontaneous action potentials (at an average frequency of $5.7 \pm 3.2 \mathrm{~Hz}$ ), as shown in the example of Figure $4 \mathrm{~b}$; in this particular case, sporadic $(<1 / \mathrm{min})$ action 
a

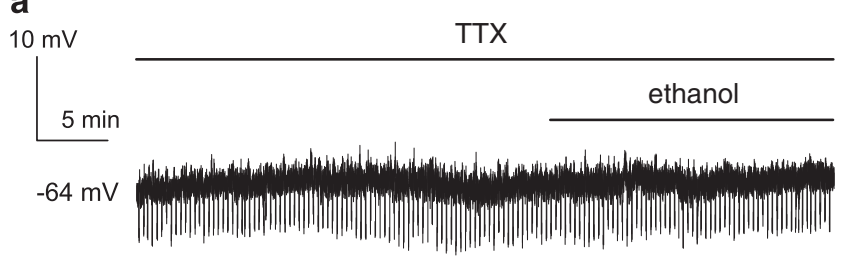

b
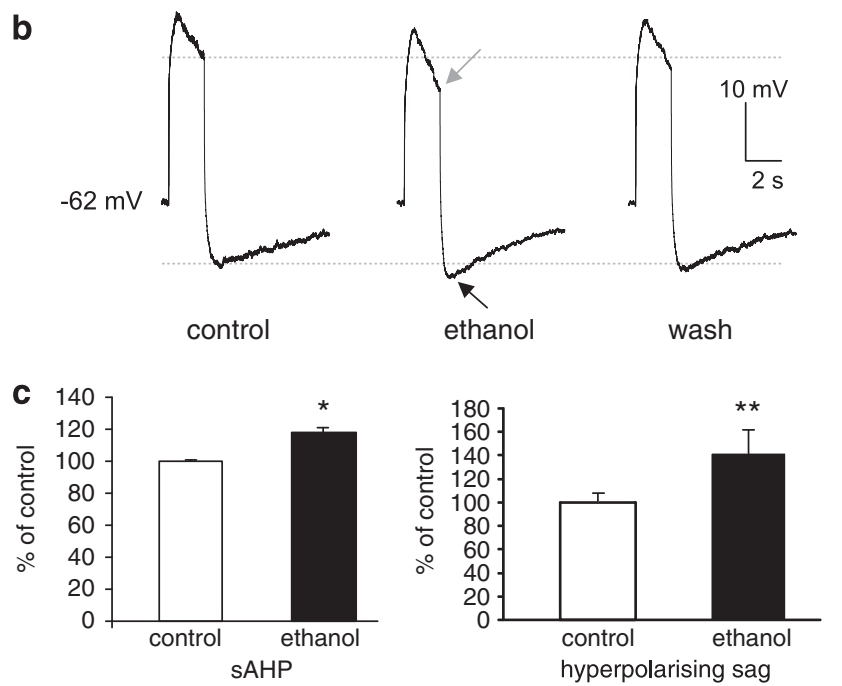

Figure 3 Ethanol's effects on LAls persist in TTX. (a) In the presence of TTX, ethanol did not affect RMP or input resistance in a LAI. (b) Injections of positive current (0.05-0.1 nA, $2 \mathrm{~s}$ ) caused depolarizations followed by hyperpolarizing sags and, after the end of the step, by afterhyperpolarizations. Both the hyperpolarizing sags (gray arrow) and the afterpolarizations (black arrow) were increased in amplitude in the presence of ethanol, and these effects were reversible on washout. (c) Average effects of ethanol on the sAHP (left) and the hyperpolarizing sag amplitude (right) in the presence of TTX (data from five LAls were normalized to average value observed in control solution $(100 \%))$. $* P=0.02$; ${ }^{*} * P=0.003$.

potentials, triggered by spontaneous synaptic events, were present in control solution, while high-frequency $(>20 \mathrm{~Hz})$ firing was triggered by ethanol. In the other three FSIs, no spontaneous firing was observed before ethanol application. Neither the amplitude nor the half-width of the fast action potentials were affected by ethanol $(n=20 ; P>0.05$ for both parameters).

In 12 FSIs depolarized by ethanol, the input resistance was monitored with small hyperpolarizing current steps. In the presence of ethanol, FSIs were manually repolarized to control level during resistance measurements. On average, input resistance in the presence of ethanol was not significantly different from the one observed in control solution $(98 \pm 3 \%)$.

In the presence of TTX, ethanol induced reversible depolarizing effects $(6 \pm 1 \mathrm{mV})$ in $5 / 5$ FSIs (Figure $4 \mathrm{c}$ ). On average, FSI input resistance measured with small current steps in the presence of ethanol was, again, not significantly different from that observed in control solution $(96 \pm 2 \%)$. In two cases ethanol was reapplied after complete washout of the effects of the first application; in both cases, the second application elicited similar depolarizing effects as the first one ( $n=2$, Figure $4 \mathrm{c})$.

In order to investigate the conductances responsible for the effects of ethanol on FSIs, we carried out slow voltage
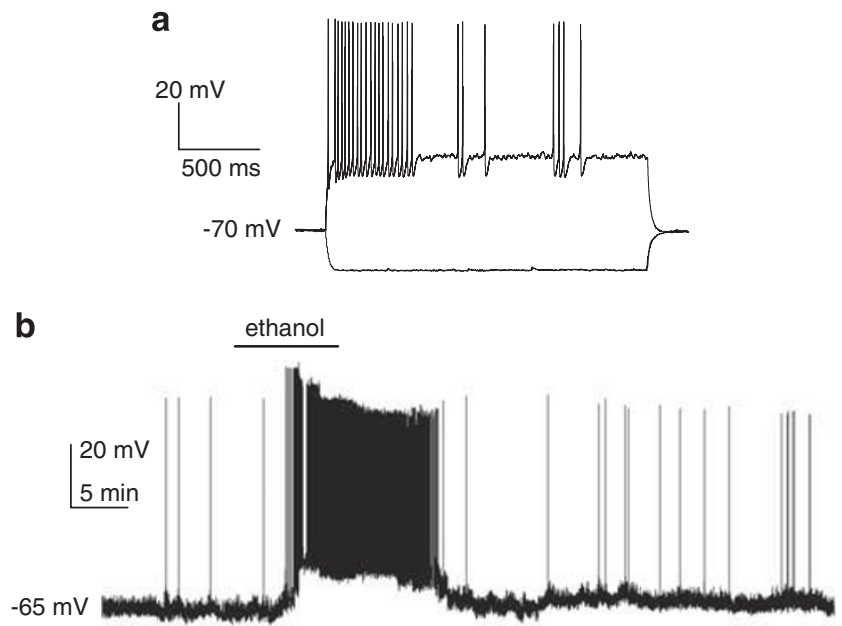

C

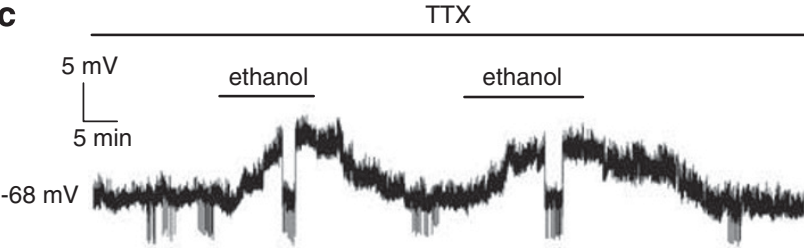

Figure 4 Excitatory effects of ethanol on FSls. (a) Typical electrophysiological properties of a FSI were revealed by current injections ( $\pm 100 \mathrm{pA}$ ). (b) In this experiment, a FSI (recorded without steady current injection) displayed a low level of spontaneous firing activity in control solution (on average, $0.1 \mathrm{~Hz}$ during the $5 \mathrm{~min}$ preceding ethanol application). Ethanol induced a large depolarization ( $14 \mathrm{mV}$ ) accompanied by spontaneous bursts of action potentials (on average, $2.9 \mathrm{~Hz}$ over $5 \mathrm{~min}$ in the presence of ethanol). Subsequent washout of ethanol repolarized the FSI to control level and produced similar levels of spontaneous firing (on average, $0.2 \mathrm{~Hz}$ over $5 \mathrm{~min}$ after ethanol washout). (c) Ethanol (50 mM) reversibly depolarized a FSI in the presence of TTX (I $\mu \mathrm{M})$. Input resistance was monitored using current pulses (I5pA, $500 \mathrm{~ms})$. During the depolarization induced by ethanol, the FSI was manually repolarized to control level, to measure input resistance. No significant changes in input resistance were observed in the presence of ethanol. A second application of ethanol after washout caused similar depolarizing effects as the first application.

ramp experiments in the presence of TTX (see Materials and Methods for details). In 6/11 cases, ethanol suppressed a current that reversed close to the nominal reversal potential for potassium $(-100 \mathrm{mV})$, and displayed both inward rectification (at potentials more negative than $-90 \mathrm{mV}$ ) and outward rectification (at potentials more positive than $-30 \mathrm{mV}$ ), as illustrated in the example of Figure 5. In all six cases, this current was characterized by a very low $(<1 \mathrm{pA} / \mathrm{mV})$ slope conductance in the voltage region between -80 and $-60 \mathrm{mV}$, a finding consistent with the lack of significant effects of ethanol on FSI input resistance. On average, in these neurons, ethanol-suppressed currents reversed polarity at $-99 \pm 6 \mathrm{mV}$. In $3 / 11$ FSIs, ethanol had different effects, inducing a current that reversed at $-43 \pm 4 \mathrm{mV}$ (not shown). No measurable effects of ethanol were observed in the remaining 2/11 FSIs.

Thus, the main mechanism underlying ethanol's excitatory effects on FSIs was the suppression of potassium current(s) characterized by inward and outward rectification, whereas a putative cationic current (inward in the RMP region) was increased by ethanol in a minority of FSIs. 

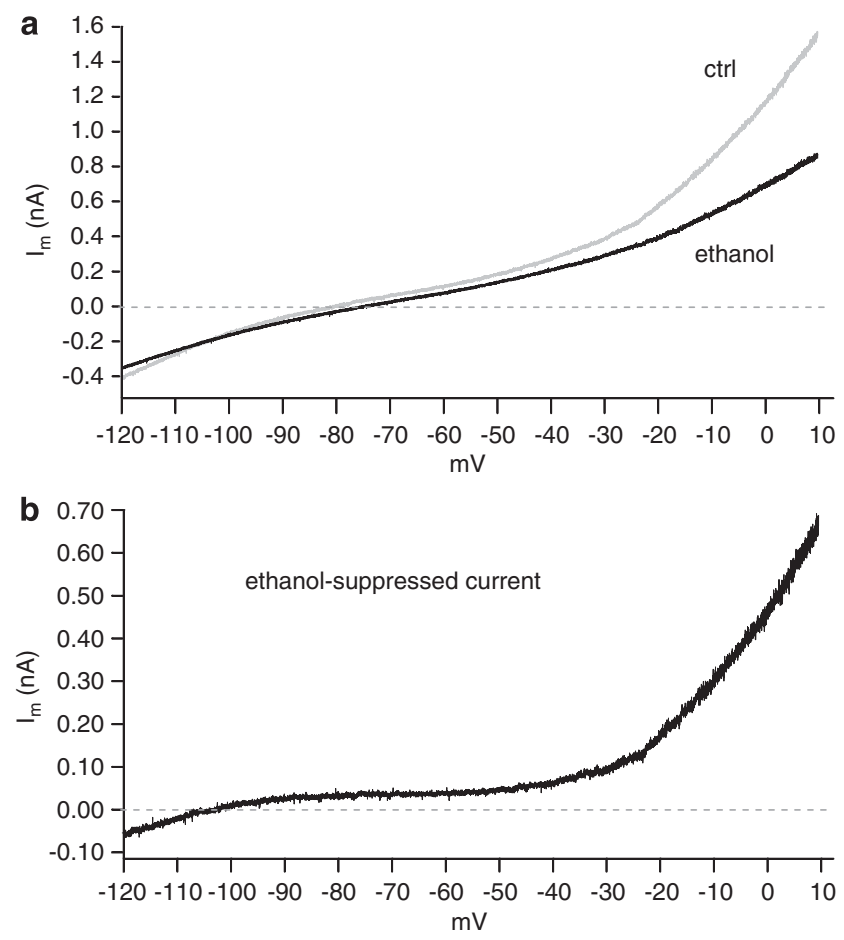

Figure 5 Ethanol suppresses potassium currents in FSIs. (a) A representative example of the voltage-clamp experiments carried out in the presence of TTX. A voltage ramp (from - 120 to $-20 \mathrm{mV}, 10 \mathrm{mV} / \mathrm{ms}$ ) was applied to a FSI, in the absence and in the presence of ethanol. Membrane currents are plotted vs voltage in control solution (gray) and in the presence of ethanol (black). (b) Voltage dependence of the ethanolsuppressed currents in the same FSI. The steady-state current induced by ethanol was calculated, for each voltage, by subtracting the membrane current measured in control solution from that measured in the presence of ethanol. Ethanol-suppressed current reversed at $-102 \mathrm{mV}$.

\section{Effects of Ethanol on LTSIs}

The electrophysiological features of LTSIs included: (1) very high input resistance $(670 \pm 53 \mathrm{M} \Omega)$, and (2) the ability to generate low-threshold calcium spikes in response to depolarizing current pulses and immediately after hyperpolarizing ones (Figure 6a). Average RMP for these cells was $-55 \pm 7 \mathrm{mV}$. In experiments carried out on BAC-npy mice, LTSIs were visually selected based on their fluorescence, but only classed as such if they also displayed the electrophysiological properties mentioned above.

In 20/21 rat LTSIs recorded under current-clamp conditions, bath application of ethanol elicited a slow and reversible membrane hyperpolarization. On average, the peak amplitude of ethanol-induced hyperpolarizations was $5 \pm 3 \mathrm{mV}$. Neither the amplitude nor the duration of the action potentials was affected by ethanol. In most cases, LTSI did not exhibit spontaneous action potential generation. However, consistent with previous reports (Partridge et al, 2009), spontaneous firing activity was observed in three LTSs, as shown in the example of Figure $6 \mathrm{~b}$. In each of these LTSs, acute ethanol application caused a complete disappearance of spontaneous action potentials (Figure 6b). Ethanol also elicited similar hyperpolarizations $(6 \pm 2 \mathrm{mV})$ in 4/4 LTSIs when applied in the presence of TTX (Figure 6c). As in control solution, these hyperpolarizations a
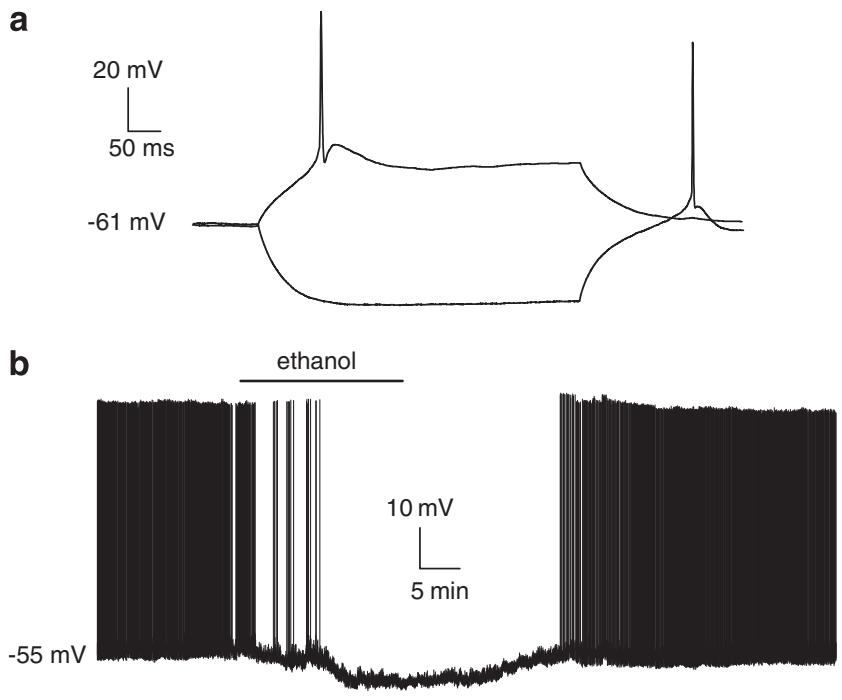

C

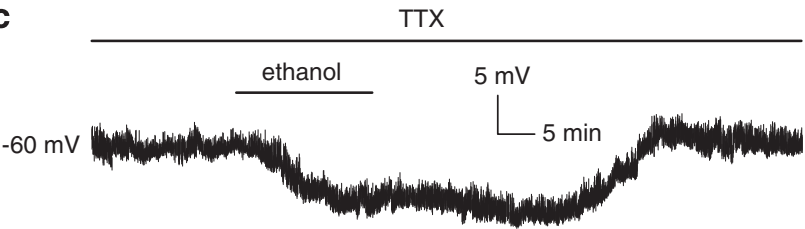

Figure 6 Inhibitory effects of ethanol on LTSs. (a) Typical electrophysiological properties of an LTSI were revealed by current injections $( \pm 25 \mathrm{pA})$. (b) In this experiment, an LTSI (recorded without steady current injection) displayed a spontaneous firing activity in control solution (on average, $2.1 \mathrm{~Hz}$ during the $5 \mathrm{~min}$ preceding ethanol application). Ethanol induced a strong hyperpolarization $(8 \mathrm{mV})$ that completely abolished spontaneous firing. Subsequent washout of ethanol repolarized the FSI to control level and produced similar levels of spontaneous firing (on average, $1.7 \mathrm{~Hz}$ over $5 \mathrm{~min}$ after ethanol washout). (c) In the presence of TTX ( I $\mu \mathrm{M}$ ), ethanol $(50 \mathrm{mM})$ reversibly hyperpolarized an LTSI by $9 \mathrm{mV}$.

were not accompanied by significant changes in membrane input resistance. These finding indicated that the inhibitory effects of ethanol on LTSIs were because of a direct action on these cells.

Similar effects were observed during current-clamp experiments in LTSIs from BAC-npy mice: under currentclamp conditions, ethanol induced hyperpolarizing effects $(5 \pm 2 \mathrm{mV})$ in $3 / 3 \mathrm{BAC}-n p y$ mice LTSIs. In order to further investigate the conductances modulated by ethanol in LTSIs, we carried out slow ramp voltage-clamp experiments (see Materials and Methods for details) in the presence of TTX; these experiments were performed on BAC-npy mice. LTSI I-V relationships were characterized by marked outward rectification and in most cases (9/16) by a region of negative slope (two representative examples are shown in Figure $7 \mathrm{a}$ and $\mathrm{d}$ ). In 13/16 LTSIs, ethanol induced an outward current that appeared when the holding potential became more positive than a level that varied, in different neurons, between -65 and $-50 \mathrm{mV}$ (Figure $7 \mathrm{a}, \mathrm{b}, \mathrm{d}$, and e). Upon return to holding potential, an outward tail current was present, similar to that observed in previous studies and caused by the calcium-activated potassium conductances responsible for the sAHP (Goldberg and Wilson, 2005). In 6 out of the 13 LTSIs in which ethanol induced the outward current described above, the peak value of the tail current was significantly $(P<0.05$; at least 10 ramps per 

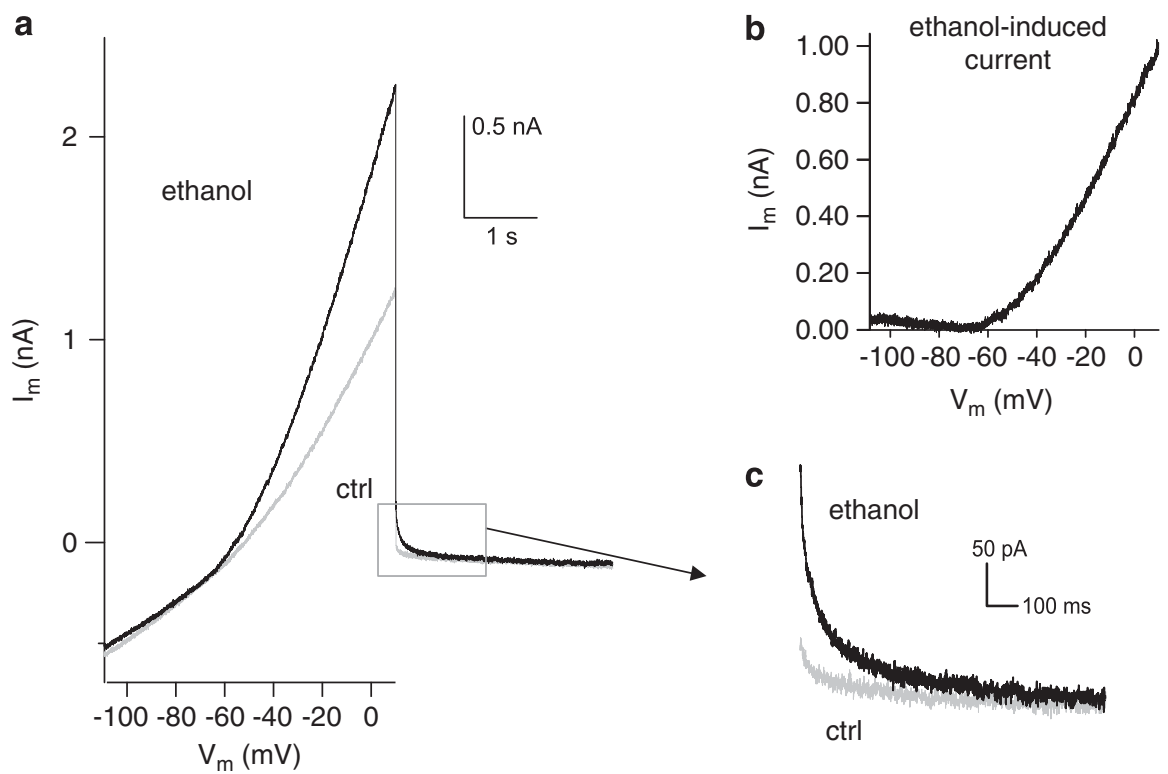

C
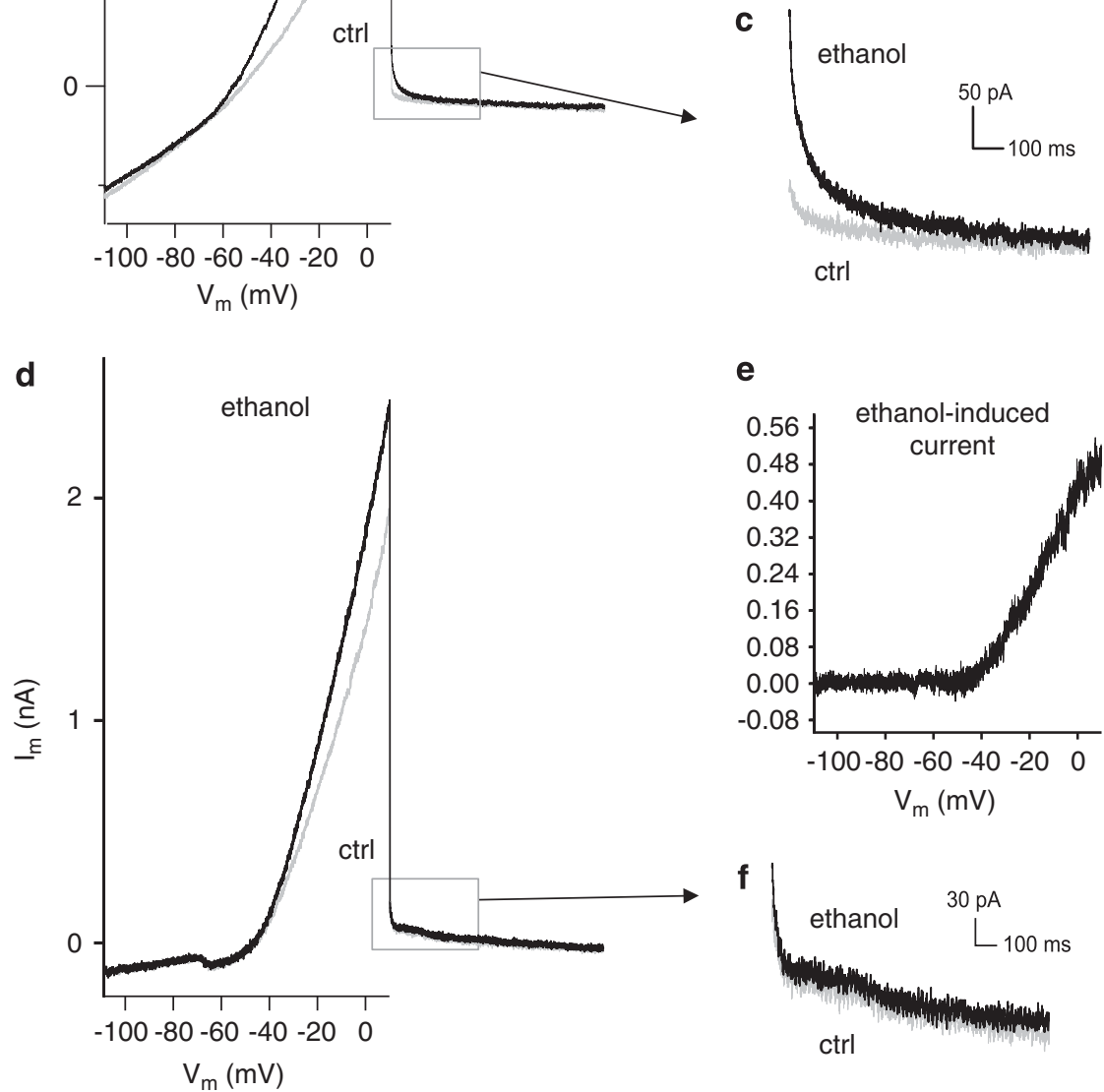

Figure 7 Ethanol increases voltage-dependent outward currents in LTSIs. (a) An example of the voltage-clamp experiments carried out in the presence of TTX. Voltage ramps (from - I 10 to $10 \mathrm{mV}, 10 \mathrm{mV} / \mathrm{ms}$ ) were applied to an LTSI, before and after ethanol application. Membrane currents are plotted vs voltage in control solution (gray) and in the presence of ethanol (black). (b) Voltage dependence of the ethanol-induced current in the same LTSI. The steady-state current induced by ethanol was calculated, for each voltage, by subtracting the membrane current measured in the presence of ethanol control solution from that measured before ethanol application. (c) Enlargement of a portion of the traces in (a), showing the tail currents observed after the ramp upon repolarization to $-60 \mathrm{mV}$. In this LTSI, ethanol significantly increased tail currents. (d) In a different LTSI, the slow-ramp current displayed a region of negative slope. As in the previous example, ethanol induced a voltage-dependent outward current, but in this case the tail current observed upon repolarization was not significantly affected by ethanol. (e) Voltage dependence of the ethanol-induced current in the LTSI of panel (d). The steady-state current induced by ethanol was calculated, for each voltage, by subtracting the membrane current measured in the presence of ethanol control solution from that measured before ethanol application. ( $f$ Enlargement of a portion of the traces in (d), showing the tail currents observed after the ramp upon repolarization to $-60 \mathrm{mV}$. In this LTSI, ethanol did not significantly affect tail currents.

condition per neuron) increased in the presence of ethanol (on average by $576 \pm 830 \%$ ), as shown in the example of Figure $7 \mathrm{a}$ and $\mathrm{c}$. However, in the other 7/11 LTSIs, the tail current was not significantly affected by ethanol. An example of the latter behavior is illustrated in Figure $7 \mathrm{~d}$ and e. There was no apparent correlation between the presence of a negative slope area in the $\mathrm{I}-\mathrm{V}$ curve and the modulation of the tail current by ethanol. Thus, the LTSI population displayed heterogeneity in both its membrane properties and ethanol responses. The outward currents induced by ethanol in LTSIs may be carried by either potassium or chloride ions. In four LTSIs recorded with high-chloride intracellular solution (which is expected to depolarize $\mathrm{E}_{\mathrm{Cl}}$ strongly, see Materials and Methods for details), ethanol induced an outward current similar in its voltage dependence to that observed with normal intracellular solution (not shown). Thus, the ethanol-induced current was not mediated by chloride, and was likely to 
be mainly caused by an increase in potassium conductances, including (in a subgroup of LTSIs) calciumactivated ones.

\section{Effects of Ethanol on MSNs}

MSNs had hyperpolarized RMPs (on average $-83 \pm 4 \mathrm{mV}$ ), strong inward rectification, and produced slow depolarizing ramps and delayed action potentials during positive current injections (Nisenbaum and Wilson, 1995). The average input resistance was $191 \pm 36 \mathrm{M} \Omega$. Typical MSN responses to current injections are illustrated in Figure $8 \mathrm{a}$.

In control solution, bath application of ethanol $(50 \mathrm{mM})$ caused hyperpolarizations $(5 \pm 2 \mathrm{mV})$ in $11 / 15$ MSNs. Such hyperpolarizations were accompanied by a significant $(P<0.01)$ decrease $(47 \pm 3 \%)$ in input resistance (measured while the MSNs were manually repolarized to control level). A representative example of these effects is shown in Figure $8 \mathrm{~b}$. These effects were reversible upon washout of ethanol (10-20 min). Re-application of ethanol after washout caused effects similar to those of the first application (not shown). In the remaining four MSNs, ethanol did not significantly affect RMP or input resistance.

In contrast to what we observed in striatal interneurons, when ethanol was applied in the presence of TTX, it failed to elicit significant effects on either the RMP or input resistance in 8/8 MSNs tested. A representative example of these experiments is shown in Figure 8c. This observation shows that ethanol did not affect MSNs directly, and that its effects were because of actions on other surrounding striatal neurons. As described above, the spontaneous firing of LAIs was found to be inhibited by ethanol; activation of M1 muscarinic receptors is known to depolarize MSNs by suppressing potassium currents mediated by Kir2 and KCNQ channels (Shen et al, 2005, 2007); the effects of ethanol on MSNs (hyperpolarization and decrease in input resistance) were consistent with an increase in potassium conductance. Therefore, we decided to test the hypothesis that the effects of ethanol on MSNs in control solution were because of decreased cholinergic tone causing a reduction in the activation of M1 receptors. In order to do this, we used the selective $\mathrm{M} 1$ receptor antagonist telenzepine (100 nM) in six experiments (using six different slices); in these experiments, illustrated by the example of Figure $8 d$, the hyperpolarizing effects $(3 \pm 1 \mathrm{mV})$ of a first application of ethanol on MSNs were reversed on washout; at this point, telenzepine was bath applied, causing per se hyperpolarizations $(7 \pm 2 \mathrm{mV})$ in the MSNs. In the presence of telenzepine, a second ethanol application failed to affect the MSN membrane potential or input resistance (again measured while the MSNs were repolarized to resting level, as shown in Figure 8d). This showed that the effects of ethanol on MSNs were caused by a decrease in the basal levels of acetylcholine in the striatum and a consequent decrease in the activation of postsynaptic M1 receptors. As Kir2, but not KCNQ, channels are open at RSMs in MSNs (Shen et al, 2005), it seemed likely that the hyperpolarizations induced by ethanol were because of decreased muscarinic suppression of Kir2 channels. To test this hypothesis, we conducted experiments in which ethanol was initially applied and washed out in MSNs. Subsequently, a low dose of barium $(100 \mu \mathrm{M})$, which selectively blocks Kir
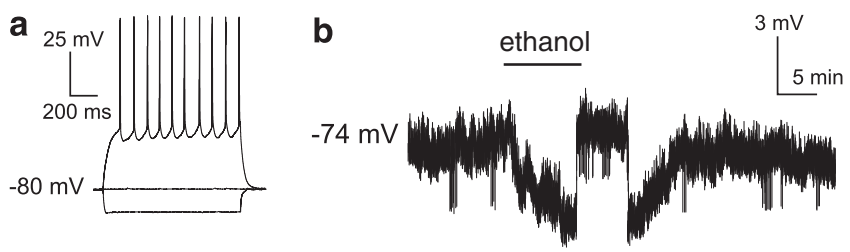

C

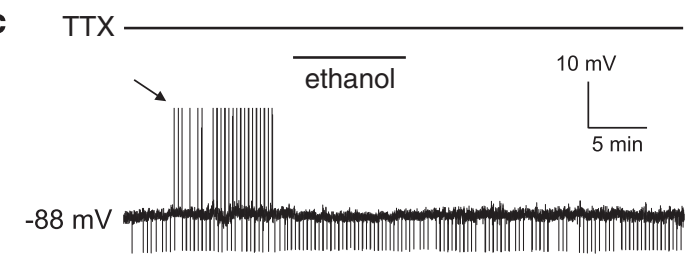

d
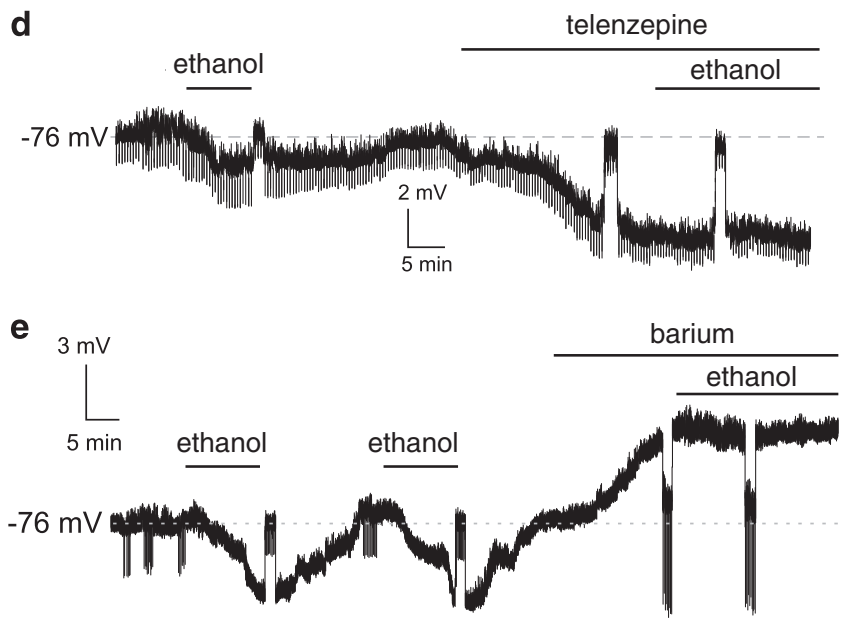

Figure 8 The inhibitory effects of ethanol on MSNs require $\mathrm{MI}$ muscarinic receptor activation. (a) Typical responses of a MSN to positive and negative current injections $( \pm 150 \mathrm{pA})$. Note the depolarizing ramp causing delayed firing, and the smaller extent of responses to negative steps, indicative of inward rectification. (b) Ethanol $(50 \mathrm{mM})$ reversibly hyperpolarized a MSN in control solution. Input resistance was monitored using current pulses (10 pA, $500 \mathrm{~ms}$ ) applied every $10 \mathrm{~s}$. During the hyperpolarization induced by ethanol, the MSN was manually repolarized to control level, to measure input resistance. A significant $(P<0.05)$ decrease in input resistance was observed during ethanol application. (c) In the presence of TTX $(I \mu M)$, ethanol did not produce any significant effect on either RMP or input resistance. Truncated vertical deflections (arrow) are responses to suprathreshold current injection that were used to monitor the effects of TTX on the MSN. By the time ethanol was applied, the MSN had completely lost its ability to generate sodium action potentials. (d) In this experiment, bath application of ethanol caused a hyperpolarization $(\sim 3 \mathrm{mV})$ in a MSN, from a RMP of $-76 \mathrm{mV}$ and a significant $(P<0.05)$ decrease in input resistance that were both reversible upon washout. Subsequent application of the muscarinic $\mathrm{MI}$ receptor antagonist telenzepine dihydrochloride $(100 \mathrm{nM})$ produced a larger hyperpolarization $(6 \mathrm{mV})$ that was also accompanied by a significant $(P<0.05)$ decrease in input resistance. Subsequent re-application of ethanol (still in the presence of telenzepine) produced no further effect on RMP or input resistance, which was measured during manual repolarizations to control level. (e) In another experiment, two consecutive applications of ethanol, separated by a washout period, caused similar, reversible hyperpolarizing responses in a MSN. These responses were accompanied by a significant decrease in input resistance. Subsequent application of $100 \mu \mathrm{M}$ barium (after washout of the second ethanol application) depolarized the MSN and strongly increased its input resistance. In the presence of barium, application of ethanol failed to affect the MSN membrane potential or its input resistance. During each treatment, the neuron was transiently repolarized to approximately resting level and current steps were injected to test its input resistance. 
channels (Wilson, 2005), was applied and ethanol was reapplied in the presence of barium. In 6/6 MSNs that displayed hyperpolarizing responses to ethanol in control solution, barium caused membrane depolarizations (on average, $6 \pm 1 \mathrm{mV}$ ) and large increases in input resistance (on average, to $190 \pm 27 \%$ of control); in all cases, re-application of ethanol in the presence of barium failed to affect MSN membrane potential or input resistance. An example of these experiments is illustrated in Figure 8e. In this particular experiment, ethanol was applied and washed out twice in control solution (with similar effects) before barium application. We concluded that the effects of ethanol on MSNs were mediated by barium-sensitive Kir2 channels.

\section{Effects of Ethanol on Evoked MSN Synaptic Responses}

In order to gain a complete picture of the effects of ethanol on striatal projection neurons, we investigated its effects on evoked synaptic potentials. Previous studies have shown that ethanol decreases MSN fast glutamatergic responses mediated by NMDA receptors (Wang et al, 2007; Yin et al, 2007), as well as those mediated by non-NMDA receptors (Choi et al, 2006). We confirmed these earlier results by testing the effects of ethanol on non-NMDA receptormediated responses; ethanol reversibly decreased evoked EPSC amplitude, without significantly affecting the pairedpulse ratio (at $100 \mathrm{~ms}$ intervals) of the evoked responses. These results are illustrated in Supplementary Figure 2.

We then investigated the effects of ethanol on evoked IPSCs mediated by $\mathrm{GABA}_{\mathrm{A}}$ receptors (see Materials and Methods for details). Ethanol significantly $(P<0.01)$ decreased the amplitude of the evoked IPSCs in 7/8 MSNs, as shown in Figure 9a; average results are plotted in Figure 9b. The paired-pulse ratio (intervals of $200 \mathrm{~ms}$ ) was not significantly affected by ethanol in all cases.

Stimulation of thalamostriatal fibers in a horizontal brain slice preparation has been recently shown to activate LAIs and to affect corticostriatal responses of MSNs through activation of presynaptic muscarinic receptors (Ding et al, 2010). We decided to use this protocol to explore the effects of ethanol at a network level involving LAIs and MSNs. In order to do this, we recorded from MSNs under currentclamp conditions in horizontal slices while stimulating corticostriatal and thalamostriatal fibers, as described in the Materials and Methods. As reported by Ding et al (2010), in control solution a train of 25 thalamic stimuli $(50 \mathrm{~Hz})$ caused a significant $(P<0.01)$ reduction in the amplitude of glutamatergic responses elicited by single cortical stimuli $5 \mathrm{~s}$ after the train in 6/6 MSNs tested (on average this reduction was $26 \pm 9 \%)$. Consistent with the results described above, subsequent application of ethanol caused hyperpolarizations in the MSNs, but in these experiments the cells were repolarized to resting levels by steady current injections. Consistent with previous studies (Choi et al, 2006; Wang et al, 2007), ethanol significantly reduced corticostriatal EPSP amplitude (by $31 \pm 3 \% ; P<0.001$ ). Furthermore, in the presence of ethanol, the preceding thalamic stimulation trains failed to affect significantly the corticostriatal EPSPs in 6/6 MSNs. An example of these experiments is shown in Figure $9 \mathrm{c}$, and the changes induced by ethanol on thalamic-induced reduction of corticostriatal responses are a
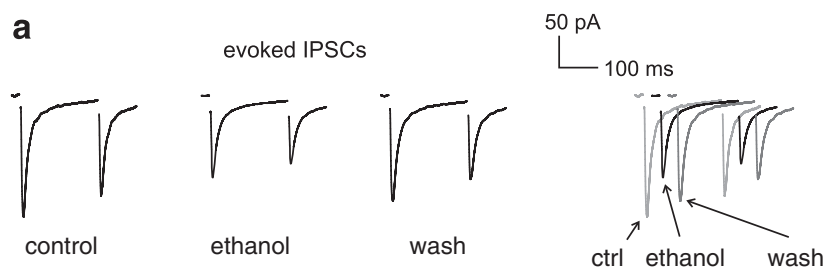

b
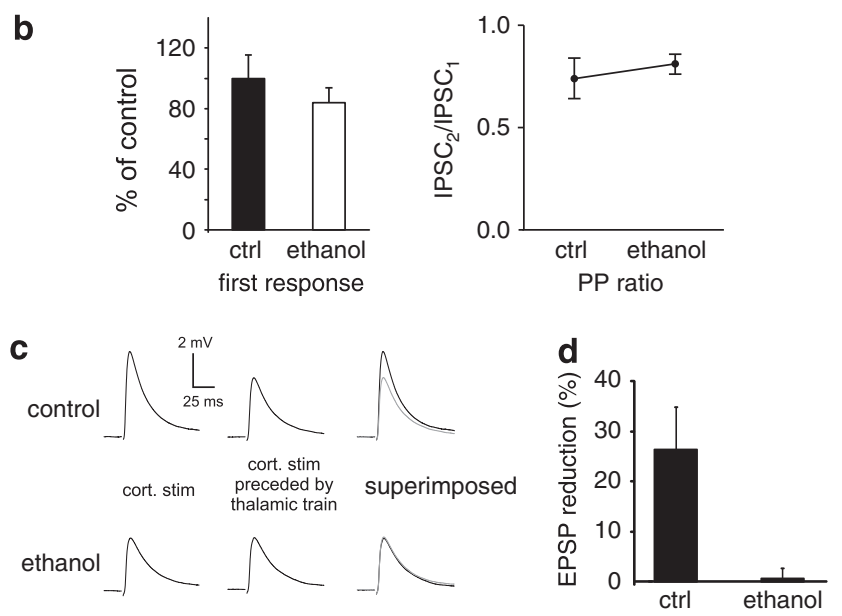

Figure 9 Ethanol reduces GABAergic synaptic responses and thalamic gating of corticostriatal inputs. (a) In this representative experiment, pairedpulse stimulation $(200 \mathrm{~ms}$ interval) was applied every $10 \mathrm{~s}$ in the presence of NBQX and AP5. The average of 50 consecutive traces is shown for each pharmacological condition. In control solution, the second response was significantly $(P<0.05)$ depressed. In the presence of ethanol, the amplitude of both IPSCs significantly $(P<0.0$ I $)$ decreased, but the paired-pulse ratio was not significantly affected. These effects were partially reversed on washout. (b) Average values for the amplitude of the first evoked IPSC and the paired-pulse ratio ( $200 \mathrm{~ms}$ interval) in control solution and in the presence of ethanol for six MSNs recorded under voltage-clamp conditions. For each cell, values were normalized to the average amplitude of the first evoked response recorded in control solution. (c) In this experiment, conducted in a horizontal brain slice, corticostriatal EPSPs were evoked in a MSN with single cortical stimuli delivered every 20 s. Every other stimulus was preceded ( 5 s) by a train of 25 thalamic stimuli at $50 \mathrm{~Hz}$ (not shown). In control solution, thalamic stimuli significantly reduced the amplitude of subsequent corticostriatal EPSPs (each trace is the average of I 00 consecutive responses for each condition). In the presence of ethanol, corticostriatal EPSPs were reduced in amplitude and were no longer affected by preceding thalamic stimuli. RMP was $-80 \mathrm{mV}$ in control solution. In the presence of ethanol, the MSN was manually repolarized at the same level with a steady current injection. (d) Average effects of a preceding thalamic stimulus train on corticostriatal EPSPs in control solution and in the presence of ethanol. Data were pooled from experiments on six MSNs.

quantified in Figure 9d. These results show that an important property of the basal ganglia loops, namely the ability of thalamic inputs to control corticostriatal EPSPs through activation of LAIs, is impaired in the presence of ethanol.

\section{DISCUSSION}

This is the first comprehensive electrophysiological study of the effects of ethanol on different neuronal subtypes in the striatum. The present data demonstrate that the effects of ethanol on striatal neurons are highly cell-type specific, as it directly inhibits LAIs and LTSs, but depolarizes FSIs, strongly increasing their excitability. Although ethanol does 
not directly affect MSNs, the reduction in acetylcholine tone causes large membrane hyperpolarizations and a reduction in input resistance in these cells. These effects are accompanied by a downregulation of both glutamate and GABA ionotropic receptors in MSNs.

The specificity of ethanol's effects on striatal interneurons appears to be a consequence of the fact that they express different sets of ionic channels (Kawaguchi, 1993), and that ethanol interacts in a highly specific manner with ion channels of different type/subunit composition (Vengeliene et al, 2008). Our experiments revealed that different currents are modulated by ethanol in each class of striatal interneurons. Calcium-activated potassium currents are potentiated by ethanol in LAIs and in a subpopulation of LTSIs, whereas one or more potassium conductances are suppressed by ethanol in FSIs.

\section{LAIs}

LAIs are spontaneously active both in vivo and in vitro, thanks to a dynamic interplay of several voltage-dependent membrane conductances (Bennett and Wilson, 1999; Wilson, 2005) The calcium-activated potassium conductances responsible for the medium and slow AHPs are particularly prominent, and have an important role in shaping the firing patterns of cholinergic interneurons (Wilson, 2005). The mAHP is because of rapid SK calciumactivated potassium channels that are associated with $\mathrm{N}$-type calcium channels, whereas the sAHP is associated with L-type channels (Goldberg et al, 2009; Goldberg and Wilson, 2005). The present results show that ethanol strongly potentiates these currents, and this results in a marked decrease in the rate of spontaneous action potentials, both in regularly firing LAIs and in burstiform ones. These recordings were carried out with the gramicidin perforated-patch technique, which minimizes disruption of the intracellular environment, and is required to preserve the membrane properties of LAIs (Blomeley and Bracci, 2005; Wilson, 2005). Experiments in the presence of TTX revealed that the sAHP was strongly augmented by ethanol, whereas other conductances active at rest were not affected. The intrinsic limitations of perforated-patch techniques prevented us from testing the effects of ethanol on the much faster currents responsible for the mAHP in the presence of TTX. However, in other neurons, ethanol is well known to potentiate apamin-sensitive BK channels (Brodie et al, 2007; Treistman and Martin, 2009), which are responsible for mAHP in LAIs (Goldberg and Wilson, 2005); thus, it is likely that a similar direct interaction was responsible for the ethanol-induced increase in mAHP following individual spikes. We previously showed that serotonin reversibly reduces the mAHP and sAHP in LAIs (Blomeley and Bracci, 2005). The convergence of effects of ethanol and 5-HT on the same membrane mechanisms is relevant to the complex field of the pharmacological interactions between alcohol and the antidepressant drugs that inhibit serotonin reuptake (Caldwell and Miczek, 2008).

\section{LTSIs}

Ethanol hyperpolarized LTSIs by potentiating persistent voltage-dependent outward currents that became active in a membrane potential range comprised between -65 and $-50 \mathrm{mV}$; although the exact nature of these ethanol-induced outward currents was not determined, we can exclude that chloride conductances had a major role. In fact, the voltage dependence of these currents was not substantially different in LTSIs that were recorded with a high-chloride internal solution, which shifts the nominal reversal potential for chloride from -55 to $1 \mathrm{mV}$. In a subgroup of LTSIs, ethanol also markedly increased the tail currents that followed prolonged depolarizations; these tail currents are attributable to the engagement of the calcium-activated potassium conductances responsible for sAHPs (Goldberg and Wilson, 2005). In addition to these differences in the features of ethanol modulation, our experiments also revealed heterogeneity in the LTSI population in terms of their I-V relationships, although the two were not correlated. In spite of this diversity, it should be noted that ethanol produced strong hyperpolarizing responses in almost all LTSIs tested. A recent study has suggested that the ability of LTSIs to influence MSNs through GABAergic connection is modest, and that these cells are likely to exert their influence mainly through other neurotransmitters, which include nitric oxide, somatostatin, and NPY (Gittis et al, 2010). The inhibition of LTSIs by ethanol, and the complete disappearance of spontaneous firing when present in control solution, suggests that these neuromodulators will dramatically decrease in the striatum during ethanol intoxication.

\section{FSIs}

In sharp contrast with the other interneuronal types, FSIs were strongly depolarized by ethanol, which also elicited spontaneous firing in some of these cells. These effects, which persisted in TTX, were because of the reduction of potassium currents that exhibited both inward and outward rectification. The relative rarity of striatal FSIs has so far prevented a systematic analysis of the membrane conductances expressed by these cells. In current-clamp experiments, FSIs display waveforms indicative of inward rectification (Bracci et al, 2003; Kawaguchi, 1993), presumably mediated by potassium conductances of the Kir family (Hibino et al, 2010; Nisenbaum and Wilson, 1995). That ethanol suppresses (in FSIs) or increases (in LAIs and LTSIs) potassium currents is not surprising, in light of the highly idiosyncratic interactions of this substance with membrane proteins (Dopico and Lovinger, 2009; Vengeliene et al, 2008). In other structures, ethanol activates $G$ proteingated inwardly rectifying potassium channels (GIRKs), but inhibits constitutively open inward rectifying channels such as IRK1, as well as other potassium channels (Appel et al, 2003; Aryal et al, 2009). Furthermore, ethanol inhibits quinidine-sensitive potassium currents in midbrain dopaminergic neurons, but potentiates their $\mathrm{GABA}_{\mathrm{B}}$ receptormediated inhibition by facilitating GIRK currents (Appel et al, 2003; Federici et al, 2009).

\section{MSNs}

The experiments carried out in the presence of TTX clearly showed that ethanol did not exert a direct action on MSN membrane currents. MSNs display very prominent inward rectification mediated by Kir2 channels (Nisenbaum and 

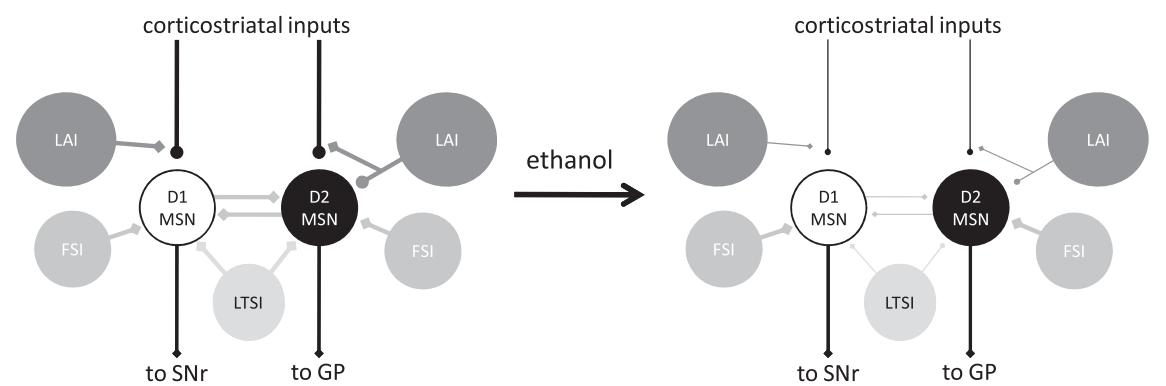

Figure 10 Summary of the main changes induced by ethanol on the excitatory and inhibitory inputs to MSNs. In the presence of ethanol, all the GABAergic inputs to MSNs are reduced with the possible exception of those arising from FSIs, for which a decrease in synaptic efficacy is compensated by the increased excitability of these cells. Glutamatergic inputs are also reduced; inhibition of LAls also decreases cholinergic signaling, which normally inhibit glutamate release acting presynaptically and exert excitatory influence on striatopallidal MSNs through postsynaptic mechanisms involving Kir2 channels. Excitatory connections are represented by circles and inhibitory connections by diamonds.

Wilson, 1995; Shen et al, 2007); the present experiments suggest that these channels are different in type or subunit composition by the inward rectifying channels suppressed by ethanol in FSIs as well as in other brain areas (as discussed above). This is consistent with the heterogeneous nature of this class of the Kir family channels (Hibino et al, 2010). Nevertheless, in control solution MSNs were strongly hyperpolarized by ethanol, and this effect was entirely dependent on receptors sensitive to telenzepine (a relatively selective M1 muscarinic receptor antagonist). In fact, telenzepine per se caused a marked hyperpolarization of MSNs, and prevented further actions of ethanol on these cells. This observation, combined with the strong inhibitory effects of ethanol on LAIs spontaneous activity, showed that MSN hyperpolarizations were because of a decrease in acetylcholine tone in the striatum. This is expected to reduce the tonic activation of M1 receptors, which strongly suppress KCNQ and Kir2 currents in striatopallidal MSNs (Shen et al, 2007). These findings are consistent with previous studies showing that tonic levels of acetylcholine in the striatum cause substantial activation of M1 muscarinic receptors in MSNs (Narushima et al, 2007). The presence of tonic levels of acetylcholine has also been reported to have an important role in long-term synaptic plasticity (Wang et al, 2006), although these findings have been disputed (Kreitzer and Malenka, 2007). The effects of ethanol on MSNs were completely abolished by low concentrations of barium, which selectively blocks Kir2 channels (Wilson, 2005). This is consistent with the fact that KCNQ channels only display substantial activation at membrane potentials more positive than $-60 \mathrm{mV}$, and are therefore unlikely to contribute to their hyperpolarizations from RSMs (approximately $-80 \mathrm{mV}$ ). It is likely that the MSNs that did not respond to ethanol were mainly striatonigral projection cells, as these neurons are not depolarized by M1 receptor activation (Shen et al, 2007).

These indirect effects of ethanol on MSNs were accompanied by a marked reduction in GABAergic synaptic inputs; given these findings, and the previously shown reduction in ionotropic glutamate receptor-mediated responses (Choi et al, 2006; Wang et al, 2007), it can be concluded that in the presence of ethanol, the output neurons of the striatum will become much less responsive to external stimuli of both an excitatory and inhibitory nature. This effect would be exacerbated by the strong reduction in input resistance caused by decreased muscarinic receptor activation. The main effects of ethanol on the excitatory and inhibitory inputs to MSNs are illustrated in the diagram of Figure 10. This incorporates the notion mentioned above that the effects of ethanol (through M1 receptors) were mainly exerted on striatopallidal MSNs. The picture emerging from the present study should be combined with the observation that ethanol also affects long-term synaptic plasticity in the striatum (Clarke and Adermark, 2010; Yin et al, 2007).

FSIs are the main mediators of feed-forward inhibition in the striatum (Gittis et al, 2010; Tepper et al, 2008), whereas feedback inhibition is provided by MSN axon collaterals (Tepper et al, 2008; Tunstall et al, 2002); the present results suggest that the balance between these neuronal mechanisms, which is thought to be crucial for striatal information processing (Wickens et al, 2007a; Wilson, 2007), is profoundly altered in favor of feedback inhibition during ethanol intoxication (Figure 10). It will be interesting to explore the computational consequences of this shift in balance, as this may generate testable predictions on the effects of ethanol on striatal functions such as cortical pattern recognition and action selection.

LAIs respond to salient stimuli with characteristic pauses in their firing activity (Joshua et al, 2008); the resulting transient decrease in striatal acetylcholine is likely to provide MSNs with an important signal in situations that require behavioral alertness. Such a saliency signal would be impaired in the presence of ethanol, and this may contribute to decrease the ability of intoxicated subjects to react appropriately to alerting stimuli (Schweizer and Vogel-Sprott, 2008).

A recent study has revealed that activation of thalamostriatal fibers excites LAIs and depresses corticostriatal inputs to MSNs for several seconds because of the activation of presynaptic muscarinic receptors (Ding et al, 2010). Such a thalamic gating of corticostriatal inputs may be a mechanism to shift attention and redirect behavior (Ding et al, 2010). This important property of the brain loops involving the basal ganglia was strongly impaired in the presence of ethanol, presumably as a result of direct inhibition of LAIs and decreased glutamatergic inputs to these cells. Again, this observation provides a potential cellular mechanism for the attentive deficits caused by ethanol. 
In conclusion, the role of the dorsal striatum in drug addiction and ethanol consumption has been emphasized by recent studies (Jeanblanc et al, 2009; Koob and Volkow, 2010); striatal circuits have an essential role in motor control, decision making, and reward processing (Balleine et al, 2007; Surmeier et al, 2009; Wickens et al, 2007b), which are all impaired during ethanol intoxication; this suggests that this nucleus is crucially involved in producing some of the most relevant symptoms caused by ethanol intake. The present findings provide the cellular information required to understand how ethanol affects the operation of the striatum and the basal ganglia.

\section{ACKNOWLEDGEMENTS}

This study was supported by the Wellcome Trust (Grant 084706/Z/08/Z). We thank Ms Lidan Christie for her participation in early experiments on cholinergic interneurons.

\section{DISCLOSURE}

The authors declare no conflict of interest.

\section{REFERENCES}

Appel SB, Liu Z, McElvain MA, Brodie MS (2003). Ethanol excitation of dopaminergic ventral tegmental area neurons is blocked by quinidine. J Pharmacol Exp Ther 306: 437-446.

Aryal P, Dvir H, Choe S, Slesinger PA (2009). A discrete alcohol pocket involved in GIRK channel activation. Nat Neurosci 12: 988-995.

Balleine BW, Delgado MR, Hikosaka O (2007). The role of the dorsal striatum in reward and decision-making. J Neurosci 27: 8161-8165.

Bennett BD, Callaway JC, Wilson CJ (2000). Intrinsic membrane properties underlying spontaneous tonic firing in neostriatal cholinergic interneurons. J Neurosci 20: 8493-8503.

Bennett BD, Wilson CJ (1999). Spontaneous activity of neostriatal cholinergic interneurons in vitro. J Neurosci 19: 5586-5596.

Blomeley C, Bracci E (2005). Excitatory effects of serotonin on rat striatal cholinergic interneurones. J Physiol 569(Part 3): 715-721.

Blomeley CP, Bracci E (2009). Serotonin excites fast-spiking interneurons in the striatum. Eur J Neurosci 29: 1604-1614.

Blomeley CP, Kehoe LA, Bracci E (2009). Substance P mediates excitatory interactions between striatal projection neurons. J Neurosci 29: 4953-4963.

Bracci E, Centonze D, Bernardi G, Calabresi P (2003). Voltagedependent membrane potential oscillations of rat striatal fast-spiking interneurons. J Physiol 549(Part 1): 121-130.

Brodie MS, Scholz A, Weiger TM, Dopico AM (2007). Ethanol interactions with calcium-dependent potassium channels. Alcohol Clin Exp Res 31: 1625-1632.

Calabresi P, Mercuri NB, Stefani A, Bernardi G (1992). Physiological role of GABAb receptors in the mammalian neostriatum. Adv Biochem Psychopharmacol 47: 217-221.

Caldwell EE, Miczek KA (2008). Long-term citalopram maintenance in mice: selective reduction of alcohol-heightened aggression. Psychopharmacology (Berl) 196: 407-416.

Carta M, Ariwodola OJ, Weiner JL, Valenzuela CF (2003). Alcohol potently inhibits the kainate receptor-dependent excitatory drive of hippocampal interneurons. Proc Natl Acad Sci USA 100: $6813-6818$.
Carta M, Mameli M, Valenzuela CF (2004). Alcohol enhances GABAergic transmission to cerebellar granule cells via an increase in Golgi cell excitability. J Neurosci 24: 3746-3751.

Centonze D, Bracci E, Pisani A, Gubellini P, Bernardi G, Calabresi P (2002). Activation of dopamine D1-like receptors excites LTS interneurons of the striatum. Eur J Neurosci 15: 2049-2052.

Choi SJ, Kim KJ, Cho HS, Kim SY, Cho YJ, Hahn SJ et al (2006). Acute inhibition of corticostriatal synaptic transmission in the rat dorsal striatum by ethanol. Alcohol 40: 95-101.

Clarke RB, Adermark L (2010). Acute ethanol treatment prevents endocannabinoid-mediated long-lasting disinhibition of striatal output. Neuropharmacology 58: 799-805.

Deng C, Li KY, Zhou C, Ye JH (2009). Ethanol enhances glutamate transmission by retrograde dopamine signaling in a postsynaptic neuron/synaptic bouton preparation from the ventral tegmental area. Neuropsychopharmacology 34: 1233-1244.

Deschenes M, Bourassa J, Doan VD, Parent A (1996). A single-cell study of the axonal projections arising from the posterior intralaminar thalamic nuclei in the rat. Eur J Neurosci 8: 329-343.

Ding JB, Guzman JN, Peterson JD, Goldberg JA, Surmeier DJ (2010). Thalamic gating of corticostriatal signaling by cholinergic interneurons. Neuron 67: 294-307.

Dopico AM, Lovinger DM (2009). Acute alcohol action and desensitization of ligand-gated ion channels. Pharmacol Rev 61: 98-114.

Federici M, Nistico R, Giustizieri M, Bernardi G, Mercuri NB (2009). Ethanol enhances GABAB-mediated inhibitory postsynaptic transmission on rat midbrain dopaminergic neurons by facilitating GIRK currents. Eur J Neurosci 29: 1369-1377.

Ferreira MP, Willoughby D (2008). Alcohol consumption: the good, the bad, and the indifferent. Appl Physiol Nutr Metab 33: 12-20.

Gittis AH, Nelson AB, Thwin MT, Palop JJ, Kreitzer AC (2010). Distinct roles of GABAergic interneurons in the regulation of striatal output pathways. J Neurosci 30: 2223-2234.

Goldberg JA, Teagarden MA, Foehring RC, Wilson CJ (2009). Nonequilibrium calcium dynamics regulate the autonomous firing pattern of rat striatal cholinergic interneurons. J Neurosci 29: 8396-8407.

Goldberg JA, Wilson CJ (2005). Control of spontaneous firing patterns by the selective coupling of calcium currents to calcium-activated potassium currents in striatal cholinergic interneurons. J Neurosci 25: 10230-10238.

Graybiel AM (2005). The basal ganglia: learning new tricks and loving it. Curr Opin Neurobiol 15: 638-644.

Harris RA, Trudell JR, Mihic SJ (2008). Ethanol's molecular targets. Sci Signal 1: re7.

Hibino H, Inanobe A, Furutani K, Murakami S, Findlay I, Kurachi Y (2010). Inwardly rectifying potassium channels: their structure, function, and physiological roles. Physiol Rev 90: 291-366.

Jeanblanc J, He DY, Carnicella S, Kharazia V, Janak PH, Ron D (2009). Endogenous BDNF in the dorsolateral striatum gates alcohol drinking. J Neurosci 29: 13494-13502.

Joshua M, Adler A, Mitelman R, Vaadia E, Bergman H (2008). Midbrain dopaminergic neurons and striatal cholinergic interneurons encode the difference between reward and aversive events at different epochs of probabilistic classical conditioning trials. J Neurosci 28: 11673-11684.

Kawaguchi Y (1993). Physiological, morphological, and histochemical characterization of three classes of interneurons in rat neostriatum. J Neurosci 13: 4908-4923.

Koob GF, Volkow ND (2010). Neurocircuitry of addiction. Neuropsychopharmacology 35: 217-238.

Koos T, Tepper JM (1999). Inhibitory control of neostriatal projection neurons by GABAergic interneurons. Nat Neurosci 2: 467-472.

Kreitzer AC, Malenka RC (2007). Endocannabinoid-mediated rescue of striatal LTD and motor deficits in Parkinson's disease models. Nature 445: 643-647. 
Lovinger DM, White G, Weight FF (1989). Ethanol inhibits NMDA-activated ion current in hippocampal neurons. Science 243: $1721-1724$.

Mihic SJ, Ye Q, Wick MJ, Koltchine VV, Krasowski MD, Finn SE et al (1997). Sites of alcohol and volatile anaesthetic action on GABA(A) and glycine receptors. Nature 389: 385-389.

Naranjo CA, Bremner KE (1993). Behavioural correlates of alcohol intoxication. Addiction 88: 25-35.

Narushima M, Uchigashima M, Fukaya M, Matsui M, Manabe T, Hashimoto $\mathrm{K}$ et al (2007). Tonic enhancement of endocannabinoid-mediated retrograde suppression of inhibition by cholinergic interneuron activity in the striatum. J Neurosci 27: 496-506.

Nisenbaum ES, Wilson CJ (1995). Potassium currents responsible for inward and outward rectification in rat neostriatal spiny projection neurons. J Neurosci 15: 4449-4463.

Pakhotin P, Bracci E (2007). Cholinergic interneurons control the excitatory input to the striatum. J Neurosci 27: 391-400.

Partridge JG, Janssen MJ, Chou DY, Abe K, Zukowska Z, Vicini S (2009). Excitatory and inhibitory synapses in neuropeptide Y-expressing striatal interneurons. J Neurophysiol 102: 3038-3045.

Partridge JG, Tang KC, Lovinger DM (2000). Regional and postnatal heterogeneity of activity-dependent long-term changes in synaptic efficacy in the dorsal striatum. J Neurophysiol 84: $1422-1429$.

Pisani A, Bonsi P, Centonze D, Martorana A, Fusco F, Sancesario G et al (2003). Activation of betal-adrenoceptors excites striatal cholinergic interneurons through a cAMP-dependent, protein kinase-independent pathway. J Neurosci 23: 5272-5282.

Plotkin JL, Wu N, Chesselet MF, Levine MS (2005). Functional and molecular development of striatal fast-spiking GABAergic interneurons and their cortical inputs. Eur J Neurosci 22: 1097-1108.

Popp RL, Lickteig R, Browning MD, Lovinger DM (1998). Ethanol sensitivity and subunit composition of NMDA receptors in cultured striatal neurons. Neuropharmacology 37: 45-56.

Redgrave P, Coizet V (2007). Brainstem interactions with the basal ganglia. Parkinsonism Relat Disord 13(Suppl 3): S301-S305.

Schweizer TA, Vogel-Sprott M (2008). Alcohol-impaired speed and accuracy of cognitive functions: a review of acute tolerance and recovery of cognitive performance. Exp Clin Psychopharmacol 16: $240-250$.

Sessler FM, Hsu FC, Felder TN, Zhai J, Lin RC, Wieland SJ et al (1998). Effects of ethanol on rat somatosensory cortical neurons. Brain Res 804: 266-274.

Shen W, Hamilton SE, Nathanson NM, Surmeier DJ (2005). Cholinergic suppression of KCNQ channel currents enhances excitability of striatal medium spiny neurons. J Neurosci 25: 7449-7458.

Shen W, Tian X, Day M, Ulrich S, Tkatch T, Nathanson NM et al (2007). Cholinergic modulation of Kir2 channels selectively elevates dendritic excitability in striatopallidal neurons. Nat Neurosci 10: 1458-1466.

Smeal RM, Gaspar RC, Keefe KA, Wilcox KS (2007). A rat brain slice preparation for characterizing both thalamostriatal and corticostriatal afferents. J Neurosci Methods 159: 224-235.

Surmeier DJ, Plotkin J, Shen W (2009). Dopamine and synaptic plasticity in dorsal striatal circuits controlling action selection. Curr Opin Neurobiol 19: 621-628.

Tepper JM, Wilson CJ, Koos T (2008). Feedforward and feedback inhibition in neostriatal GABAergic spiny neurons. Brain Res Rev 58: 272-281.

Treistman SN, Martin GE (2009). BK channels: mediators and models for alcohol tolerance. Trends Neurosci 32: 629-637.

Tunstall MJ, Oorschot DE, Kean A, Wickens JR (2002). Inhibitory interactions between spiny projection neurons in the rat striatum. J Neurophysiol 88: 1263-1269.

Valenzuela CF, Bhave S, Hoffman P, Harris RA (1998). Acute effects of ethanol on pharmacologically isolated kainate receptors in cerebellar granule neurons: comparison with NMDA and AMPA receptors. J Neurochem 71: 1777-1780.

Vengeliene V, Bilbao A, Molander A, Spanagel R (2008). Neuropharmacology of alcohol addiction. Br J Pharmacol 154: 299-315.

Wang J, Carnicella S, Phamluong K, Jeanblanc J, Ronesi JA, Chaudhri $\mathrm{N}$ et al (2007). Ethanol induces long-term facilitation of NR2B-NMDA receptor activity in the dorsal striatum: implications for alcohol drinking behavior. J Neurosci 27: 3593-3602.

Wang Z, Kai L, Day M, Ronesi J, Yin HH, Ding J et al (2006). Dopaminergic control of corticostriatal long-term synaptic depression in medium spiny neurons is mediated by cholinergic interneurons. Neuron 50: 443-452.

Weiner JL, Valenzuela CF (2006). Ethanol modulation of GABAergic transmission: the view from the slice. Pharmacol Ther 111: 533-554.

Wickens JR, Arbuthnott GW, Shindou T (2007a). Simulation of GABA function in the basal ganglia: computational models of GABAergic mechanisms in basal ganglia function. Prog Brain Res 160: 313-329.

Wickens JR, Budd CS, Hyland BI, Arbuthnott GW (2007b). Striatal contributions to reward and decision making: making sense of regional variations in a reiterated processing matrix. Ann NY Acad Sci 1104: 192-212.

Wilson CJ (2005). The mechanism of intrinsic amplification of hyperpolarizations and spontaneous bursting in striatal cholinergic interneurons. Neuron 45: 575-585.

Wilson CJ (2007). GABAergic inhibition in the neostriatum. Prog Brain Res 160: 91-110.

Wilson CJ, Goldberg JA (2006). Origin of the slow afterhyperpolarization and slow rhythmic bursting in striatal cholinergic interneurons. J Neurophysiol 95: 196-204.

Xiao C, Ye JH (2008). Ethanol dually modulates GABAergic synaptic transmission onto dopaminergic neurons in ventral tegmental area: role of mu-opioid receptors. Neuroscience 153: 240-248.

Yin HH, Park BS, Adermark L, Lovinger DM (2007). Ethanol reverses the direction of long-term synaptic plasticity in the dorsomedial striatum. Eur J Neurosci 25: 3226-3232.

Zhu PJ, Lovinger DM (2006). Ethanol potentiates GABAergic synaptic transmission in a postsynaptic neuron/synaptic bouton preparation from basolateral amygdala. J Neurophysiol 96: 433-441.

(c) Derivative Works 3.0 Unported License. To view a copy of this license, visit http://creativecommons.org/ licenses/by-nc-nd/3.0/

Supplementary Information accompanies the paper on the Neuropsychopharmacology website (http://www.nature.com/npp) 